Journal of Development and Communication Studies, Vol. 8. No. 1, January -June, 2021 ISSN (Online \& Print): 2305-7432. http://www.devcomsjournalmw.org

\title{
Corporate communication strategies: Differentiation strategies and corporate communication plan for dissemination of disease surveillance research outcomes at Kenya Medical Research Institute
}

Isaac Joseph Muthotho,Email: injoroge72@gmail.com or macsnrb943418@spu.ac.ke,Winnie Ndeta Otsiulah, Department of Communication, St. Paul's University (SPU), E Geoffrey Serede Sikolia, Department of Journalism and Communication School of Communication, Cinematic and Creative Arts, United States International University - Africa (USIU), Nairobi, Kenya.

\begin{abstract}
Globally, differentiation strategies and corporate communication plan inform corporate communication strategies, for disseminating disease surveillance research outcomes. Study respondents are also stakeholders in research outcomes alongside the scientific community. This study examined differentiation strategies and corporate communication plans, as corporate communication strategies for dissemination of research outcomes at KEMRI. It also investigated the influence of the corporate communication plan in place for dissemination of disease surveillance research outcomes to study respondents at KEMRI. The study employed a purposive sampling design utilizing mixed methods using self-administered questionnaires and in-depth interview guides. The study adopted the pragmatic research paradigm. This case study utilised descriptive study design to collect primary data. The study was anchored on excellence theory and complimented by communication theory. The Krejcie Morgan table was utilised to determine a sample size of 76 . Data was collected from a response rate of 79 per cent. From a target population of 76, the researcher purposively selected 60 respondents. The study findings were differentiation strategies (48.3\%) and corporate communication plan (51.7 per cent). Recommendations on the communication plan comprised: elevation of Corporate Affairs (CA) to top management, to manage the communication plan for disseminating research outcomes. KEMRI to incorporate a communication plan for scientists and CA, for translating research jargon to research respondents and other
\end{abstract}


stakeholders. Enhancement of differentiation strategies by continually maintaining image, identity and corporate visual identity (CVI). Empower CA to manage media relations, identity, reputation, and media audits. Propagate unified consistence in messaging, identifying KEMRI as an authority in communicating research outcomes. The study concluded that study respondents felt ignored during dissemination research outcomes at KEMRI, Nairobi. The findings enhanced the body of knowledge on, corporate communication strategies incorporating study respondents as stakeholders in research outcomes dissemination.

Keywords: corporate-communication strategies, differentiation strategies, corporatecommunication plan, disease surveillance research outcomes, Kenya

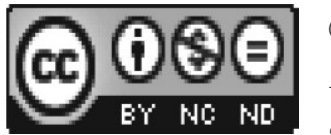

(C) 2020. The authors. This work is licensed under the Creative Commons Attribution 4.0 International License (CC-By-NC-ND). Users may freely share and redistribute this work provided that the author and the Journal of Development and Communication Studies are fully acknowledged. Users may not tweak or remix and offer this work for sale. The full license may be accessed at https://creativecommons.org/licenses/by-nc-nd/4.0/

To cite this article: Muthotho, I.J, Otsiulah, W.N. \& Sikolia, G.S. (2021). Corporate communication strategies: Differentiation strategies and corporate communication plan for dissemination of disease surveillance research outcomes at Kenya Medical Research Institute, Journal of Development and Communication Studies, 8(1), 99 - 125 https://dx.doi.org/10.4314/jdcs.v8i1.5

\section{Introduction}

Globally human health research institutions are constantly strategizing their corporate communications. The aim is to distinguish their disseminated research outcomes to remain revenant to their diverse stakeholders. According to Dixon (2017), corporate communication is a study of the internal and external communications management and strategy of a corporations efforts. To maintain, create and regain positive and productive relationships with the organisation's multiple stakeholders. Van Riel further defines corporate communication as; an instrument of management by means of which all consciously used forms of internal and external communication are, harmonised as effectively and efficiently as possible (Mohamad et al., 2018; Mohamad \& Bakar, 2018).

Moreover, corporate communication entails all communications done by an institution to its internal and external publics. Corporate communication is therefore a managerial tool. Examples include press releases, press conference, newsletters, magazines and brochures. Nwachukwu (2017) observed that efficient, effective and truthful information is the foundation of corporate communication. 
Corporate communication scholars Waslekar (2016) and Van (2018; 2020) summarised corporate communication strategies as, managerial plans to achieve institutions objectives Thus, leveraging on their competitive strength. According to Frandsen and Johansen (2017), strategic communication includes; press releases, annual reports, PowerPoint presentations and strategic plans. They communicate about the strategy of an institution. According to available literature, researchers (scientists) are inclined to communicating to collaborators and peers, as opposed to the study respondents (Yuan et al., 2017).

The history of corporate communication dates back from the productions of the Catholic Church in 1622. These included; Sacra Congregatio de Propaganda Fide, (missionaries for propagating the Faith), Vox populi, vox dei phenomemon meaning, the voice of the people is the voice of God (Kunczik, 2016; Mack, 2018). Therefore, human health research institutions in Kenya face challenges in developing corporate communication strategies, for communicating research outcomes to study respondents.

According to Okat and Solak (2020), Šerić, Ozretić-Došen and Škare (2020), differentiation strategies distinguish an institution's services from its competing counterparts. Differentiation strategies are therefore corporate communications based on institutional strengths. Moreover, differentiation strategies involve corporate branding, corporate image (CVI) and corporate visual identity (Sardana, 2018; Palazzo, Foroudi, Kitchen \& Siano, 2020). Moreover, differentiation strategies inform KEMRI's stakeholders that, it exists (Okat \& Solak, 2020; KEMRI, 2020). Thus distinguishes KEMRI's research outcomes from other research institutions. Examples in the study content, corporate identity refers to the organisation name is KEMRI. Whose slogan is, "In Search of Better Health", logo, typology is Times New Roman 12 or Calibri Light 12. Colour is sky navy blue in KEMRI's logo and publications. Thus, identifies KEMRI dealing with human health research in Kenya (KEMRI, 2020).

Keyton (2017) agrees that, a corporate communication plan is a guideline on how corporate communications are done in an organisation. Stipulates who, what and to whom is allowed to communicate (Eparkhina, Moreau, Köstner, Reilly, Ortiz, Tintore, Barbier \& Giusta, 2020). For example, who and whom and organisation like KEMRI's Corporate Affairs (CA) department sends emails or press releases (KEMRI, 2020). Furthermore, the proliferation of integrated communication technology (ICT) has necessitated institutions to strategically device plans to communicate.

\section{Problem Statement}

Human health research institutions in Kenya face challenges in developing differentiation strategies and corporate communication plan as corporate communication strategies. To communicate research outcomes to study respondents 
alongside the scientific community (Kankam-Kwarteng, Osman \& Acheampong, 2020). Thus, the challenge is to create a distinctive institutional perception in the mind of the stakeholder, of the services rendered affirms, Palazzo et al. (2020). Differentiation strategies distinguish an institution's services from its competing counterparts based on institutional strengths (Okat \& Solak, 2020; Šerić, OzretićDošen \& Škare, 2020). Whereas, the corporate communication plan is the organisational communication protocol for informing and organisational stakeholders (Bütschi, 2018). However, important findings result from the scientific work done by institutions like KEMRI. Although useful to many stakeholders, the tendency has been to communicate scientifically to other researchers.

There is a need for differentiation strategies that distinguish KEMRI's research outcomes from other research institutions. These include the institutes or organisation name, slogan, logo, colour, symbol, typology. Foroudi, Melewar and Gupta, (2017) summarised them as elements of a corporate logo. While informing stakeholders that, it exists through a corporate communication plan (Okat \& Solak, 2020; KEMRI, 2020).

Therefore, lack of differentiation strategies and corporate communication plan might lead to participant turnover (participants refusing to participate and withdrawing from study), mistrust of research outcomes. An organisation could rendered irrelevant by the government and stakeholders. Leading to a merger with other research institutions. Hence, KEMRI ought to remain an authority in dissemination of research outcomes (KEMRI, 2020).

Globally, research outcomes are disseminated in scientific forums leaving out the research respondents. According to McElfish, Purvis and Long (2018) a minority, $33 \%$ of the 3381 respondents got feedback of research outcomes. Hence, research outcomes are not accessible to all study respondents, as institutional digital platforms require internet, computer literacy and security clearance (Toomey, Alvaro, AielloLammens, Cossio \& Barlow, 2019).

According to Farrell, Kagan and Tisdall, (2016) research outcomes are presented in complex and technical jargon. Therefore, suggested the need to communicate it in a simpler language. So that potential end-users might find easier to understand and be disseminated to those audiences. Moreover, communicate health knowledge and the associated evidence-based interventions to an organisational stakeholders. Furthermore, the raising health literacy levels makes study respondents to be active publics (Blaikie \& Priest, 2019). Moreover, limited access to health information contributes to poor health decisions resulting to poverty. Ignoring study respondents could lead to demotivated study participations and respondent turn-over (WHO, 2019).

Globally, according to available literature researchers (scientists) are inclined to communicating to collaborators and peers, as opposed to the study respondents (Yuan, Oshita, AbiGhannam, Dudo, Besley \& Koh, 2017). Regionally, Nwachukwu 
(2017) emphasised institutions are obligated, to strategically communicate with their stakeholders. Wong, Hernandez and Califf (2018) study, also recommended communicating back the research outcomes to study respondents.

In Kenya, Kariuki et al. (2019) explored the research dissemination strategies used by KEMRI scientists. Kariuki highlighted a gap among scientists in KEMRI sharing research outcomes to reach the diverse stakeholders. They recommended a functional institutional repository (IR) managed by Corporate Affairs as communication plan. Thus, enhance communication between institutions and publics. The study concluded that researchers disseminated research outcomes in, international peer reviewed journals (92.7\%) between 2002 and 2015. Thus, confirmed scientific community benefited more than the study respondents.

According to Iglesias, Ind and Schultz (2020), to achieve differentiation strategies utilise corporate branding, corporate image, corporate visual identity (CVI). Keyton (2017) agrees that, a corporate communication plan is a guideline on how corporate communications are done in an organisation. Stipulates who, what and to whom is allowed to communicate (Eparkhina, Moreau, Köstner, Reilly, Ortiz, Tintore, Barbier \& Giusta, 2020).

To fill the research gap the study examined differentiation strategies and corporate communication plan, as corporate communication strategies for dissemination of disease surveillance research outcomes that include study respondents at KEMRI. Therefore, enhance best practices as corporate communication strategies for communicating with study respondents.

Research Questions (RQs). What are the differentiation strategies for dissemination of disease surveillance research outcomes to study respondents at KEMRI? How does the corporate communication plan determine the dissemination of disease surveillance research outcomes to study respondents at KEMRI?

\section{Methodology}

This case study collected primary data, utilising structured and semi-structured questionnaires and interview guides. This study utilised descriptive research design to obtain accurate information, of individuals or situations for a given period. Furthermore, descriptive design describes characteristics of the study population (Kumar, 2019). Research design is a plan, a structure a strategy to for investigation, to obtain answers to research questions (Blaikie \& Priest, 2019). Moreover, Creswell and Creswell (2017) confirm that research design is a procedure for collecting and analysis. Thereafter, reporting the research in a qualitative and quantitative research.

Therefore, this study utilised mixed methods, because of capturing rich and comprehensive data. To avoid researcher's bias, Purposive sampling process. Researcher had inclusion and exclusion criteria. Thus, ensure a rich sample. Those who can give information on communication research findings at KEMRI. Thus, to 
further understanding the research problem. Therefore, this study adopted a pragmatic paradigm, focused to answer this study's research questions. Since, each case study is unique. The design was appropriate to elicit findings from the samples, which were generalised to a greater population (Blaikie \& Priest, 2019).

According to Harriss et al. (2017), the target population (theoretical population) refers to the totality of the individuals, objects, or items under investigation to achieve study objectives. From which, samples are taken for measurement in the research study (Ghauri, Grønhaug \& Strange, 2020). Hence, this is a sum of all members of a group under review by a researcher (Blaikie \& Priest, 2019). Therefore, the target population for this study was 76. Comprising; scientists, communication staff and research respondents from on-going KEMRI studies. Hence, forming a strata comprising; Corporate Affairs (including; CIDOS - customer information desk officers) ICT and library, 14; KEMRI scientists 24; Representative research collaborators from collaborating institutions (CDC, NUITM, UW and Welcome Trust) 10; Research respondents (sourced from on-going KEMRI studies), 28 at KEMRI in Nairobi, Kenya (KEMRI HR, 2020).

The selected study respondents (purposive sampling) emanated from on-going study programmes at KEMRI for the period under review. Therefore, inclusion criteria for study participants; staff from departments that communicate (internally and externally) based at KEMRI, Nairobi. Ten respondents who answered questionnaire one were interviewed. Furthermore, this is a case study on KEMRI, specialising in human health research outcomes.

Exclusion criteria for the study; ten (10) study respondents used for pre-testing data collection tools. Respondents from KEMRI out-stations. Uncooperative and those who do consent to participate. The KEMRI scientists and collaborators must have been in KEMRI for the last one year. The ratio of researcher to respondents was be determined after, determining the sample size, using the Krejcie and Morgan table. This is because they must have constituted in disseminated research outcomes while in KEMRI.

The sample frame is the listing of members from, the accessible population from where, a sample drawn (Shuster, 2019). Hence, this study sample frame (sample size) was drawn from the listed KEMRI human resource database (KEMRI HR, 2020). Thus, individuals (staff) purposely sampled from KEMRI's departments (representative strata) whose personnel (staff) have the mandate of, corporate communication. Alongside, research respondents (from on-going projects) at based at KEMRI, Nairobi.

Moreover, sample size for the study was determined from the Krejcie and Morgan table (Krejcie \& Morgan 1970, in Saido, Siraj, Nordin \& Al-Amedy, 2018). Where $N$ is the population and $S$ is the sample size (Braun et al., 2019; Shuster, 2019). 
Therefore, the sample size was 76. Drawn from the study target population of the selected (purposed) study population using the Krejcie Morgan table. Therefore, the strata comprised; Corporate Affairs, ICT, library, scientists and research collaborators. Moreover, the sample ratio is determined by; sample size divided by size of the target population (Lohr, 2019). Hence, 0.7102803738 (76/107). The sample design is a method for selecting of study samples (Shuster, 2019; Lohr, 2019). The researcher considered two factors, as a guide in determining the sample design. First, the complexity of the research design and time to complete the research. (Braun et al., 2019).

Qualitative sampling methods are ideal in health research sampling method. Sampling methods are used to study the behaviour of individuals (Green and Thorogood 2018; Etikan \& Bala, 2017). According to Etikan and Bala (2017), purposive sampling is a non-probability sampling technique or design. Whereby, samples selected for a study meet the criteria/characteristics determined by the researcher aligned from the study objectives. The main advantage is that, the samples chosen are rich in the information under investigation. The main disadvantage being it prone to researcher's bias, as samples are specific to the researcher's interest (Lohr, 2019).

Scholars also refer to purposive sampling as; subjective, judgmental or selective, sampling. (Etikan \& Bala, 2017). However, this study utilised purposive sampling to have a representative sample unique to this case study objective. The questionnaire respondents sampled from study respondent. Whereas, interview respondents were sampled from scientific and communication staff.

According to Braun et al. (2019), a research instrument is a tool for collecting data. The study utilised researcher-generated (60) questionnaires and interview guides (10). Questionnaires and interview guides contained sets of questions printed forms in a definite order. In-depth (depth) interviews ideal where, respondents are few to achieve an objective.

The researcher sought authority to conduct the study with a recommendation letter from SPU to KEMRI. The SPU letter facilitated the researcher request official permission to conduct the academic research in KEMRI. The researcher collected the self-administered questionnaires allowed the participants enough time to answer the questions. The study employed descriptive statistical methods to leverage on the main advantage of explaining the relationship between the study variables in a sample or population. Furthermore, the quantified data in percentages presented in tables and charts (Merriam \& Grenier, 2019).

Thus, this study's data was collected, coded and cleared. The questionnaires had both close and open-ended questions. Moreover, the aim of the closed ended questions was to have control by limiting the answers in this study's demographic questions. In addition, the purpose of the open-ended questions was, to allow for more explanations (Braun et al., 2019). Furthermore, to ensure a high response rate, 
the researcher requested, Corporate Affairs (CA) to email the research tools (questionnaires and interview guides) to the study participants. The researcher confirmed the research tools were collected. Thereby, reducing disruption of the study participants work schedules. To enhance confidentiality the researcher coded the research tools.

Therefore, researcher pre-tested ten (10) of the study questionnaires and the interview guides in KEMRI, who were not be part of the data. Pre-testing ensured that there were no problems in the framing of the questions. The research instruments were pre-tested to increase validity (correctness and reliance) reliability. Errors were be checked ensuring quality and accuracy. Response rate of above $75 \%$ percent of fully completed and returned questionnaires are considered adequate (Braun et al., 2019; Merriam \& Grenier, 2019).

Reliability is the extent to with the data collection methods, generate consistent findings or outcomes, if done by other researchers (Braun et al., 2019). Hence, the consistence of a measure. Pre-testing allows for amendments of any consistencies. Thus, increase validity and reliability of the responses. Pre-testing allows discovery of errors as well as, ensuring quality and accuracy for the research.

Therefore, good reliability scores range between 0.8 and .0 .7 (Merriam \& Grenier, 2019). Moreover, pre-testing prompted the researcher where the study might fail; facilitated in designing the flow of the questions. The researcher explained the content of the questionnaires to the study participants. The researcher contacted the participants of the study through; face-to-face, telephone and email (Merriam \& Grenier, 2019).

The researcher also trained three research assistants to facilitate coding, distribution and collection of questionnaires. Therefore, reliability was be further tested by purposively selecting (multistage sampling) ten (10) participants from each cluster (category of participants) at KEMRI from the study sample frame ideal for this case a case study.

Validity is concerned with the correctness and reliance with the collected data. According to Taherdoost (2016), validity refers to the accuracy and quality assurance of inferences. Validity is the degree of which a researcher's data accurately measures, what it is intended to determine or measure (Merriam \& Grenier, 2019). Moreover, the truthfulness and realness of the study objectives or concept. Scholar, Taherdoost, (2016) summarised types of validity to include; criterion or predictive (external criteria), face validity (accurately measure study variable or individual's intuition) and construct validity, is the theoretical desired.

The researcher subjected the questionnaires and interview guides to colleagues, lecturers from communication department and the study supervisor's scrutiny to ensure that had face validity. Taherdoost (2016) also affirms that, content validly is the benchmark or a yardstick for measuring data collected. Hence, 
representing the content of concept measured. Thus, ensuring that the content in the questionnaires look relevant to the respondents.

The researcher ensured content validity by identifying the relevant items to measure the variables in the literature review and conceptual framework. Therefore, the researcher employed content validity to ensure the content is representative of this study concept and domain. Thus, consulting or engaging corporate communication gurus (experts) example, lecturers and practitioners. Thereafter, the questionnaires and the interview guide pre-checked for comprehensiveness and coherency. According to Birt et al. (2016), member checking is a tool to enhance trustworthiness or merely a nod to validation.

Data analysis is the process is of inspecting, transforming, cleaning collected information. Thereafter, coming up with conclusions that support decision-making process in an organisation (Merriam \& Grenier, 2019).

Hence, data for this research work was subjected to qualitative and qualitative analysis. The researcher presented the data in tables and charts utilising; Microsoft Excel (MS EXCEL) 2013 for data entry and cleaning. Statistical Package for Social Sciences (SPSS) version 25.0 for data analysis.

The researcher ensured the confidentiality, privacy and anonymity of the study participants. Hence, there was no coercion. Research ethics provide guidelines or codes to apply, to reconcile value and conflict. Whereas, ethics are the methods or procedures on how to act when solving an issue professionally (Ryen, 2016). Therefore, a letter of introduction to conduct the academic study was sought from St Paul's University faculty of communication and business studies. Thereafter, a student research permit was sought from, NACOSTI (student research permit license number NACOSTI/P/20/4823).

Moreover, study participant's safety and welfare and rights while conducting the study were considered. The researcher availed PPE (personal protective equipment) to study participants and research assistants to mitigate the risk of infection, inside KEMRI compound. PPE comprise; medical masks, gloves, medical masks, face shield and gowns. An example of a probable infection is (COVID-19), corona virus disease declared in March 112019 by WHO (WHO, 2020). During faceto-face interactions (collection of questionnaires and interview guides), a one-meter distance was maintained. Spray hand sanitizers (KEMRI-rub, WHO recommended) used every twenty minutes, to minimise infection. Medical facemasks, googles and latex gloves were availed (WHO, 2020; MOH, 2020; KEMRI, 2020).

Therefore, researcher ensured that the study participants were unharmed. During the research, any information gained that was personal, sensitive or confidential was treated with anonymity and confidentiality. This meant that, the information was used for research purposes only, and was not disclosed to anyone (Kumar, 2019). The names and identifiers should be changed to protect the privacy of 
participants (Green \& Thorogood, 2018). The study recommended that, the name is not mandatory to ensure anonymity and confidentiality of the participants.

\section{Literature Review}

Literature review entails explicit, systematic and reproducible method for identifying evaluating and interpreting the existing body of recorded work (Hart, 2018; Green \& Thorogood, 2018; Kumar, 2019).

Hence, literature review discusses the study objectives which are differentiation strategies and corporate communication plan, for dissemination of disease surveillance research outcomes to study respondents at KEMRI.

\section{Communication Strategies}

Van Ruler (2018) affirms that communications strategies are plans to attain an organisation's goal. They are combined communication strategies that promote the expression of the KEMRI's philosophy, mission and vision. Through the controlled and uncontrolled corporate communication. Strategy has its origins form a Greek word stratosagein, which means, building roads. Other previously used meanings include; "being the leader" and "using a ploy to win". Therefore, corporate communication strategies are plans to attain an organisation's goal. Communication strategies are avenues in which organisations objectives are realised (van Ruler, 2018).

The communication strategy of the organisation is aligned to; the mission, vision. Therefore, corporate communication is can be controlled and uncontrolled communication through various channels. Examples are text and speech (Sony, 2019; Maiorescu-Murphy, 2020). Zerfass et al. (2018) summarised strategic communication, as the purposeful use of communication to engage in discussions of strategic significance to its goals. In this context, the dissemination of research outcomes. Their study concluded that, communication is strategic if it is, purposeful and drives an institutes or organisation's mission.

Moreover, communication strategies types are; verbal, nonverbal or visual. Thus, KEMRI communicates through various (channels) media. Examples are through speeches and text. The key corporate communication elements comprise; management, marketing and organisational communications (McQuail \& Windahl, 2015). Communication strategies elements also includes; dialogue strategy (institution and stakeholders), communication strategy (information), corporate advertising strategy and dialogue strategy (interactions to disseminate knowledge) according to Frandsen and Johansen (2018). In addition, persuasive associated with, the two-way symmetrical communication model of communication.

Furthermore, Ngonyo (2018) is of the opinion that corporate communication is wrongly associated with; propaganda, liars, sugar coating experts, spies and even manipulators. Therefore, the study recommend reinstatement of government PR professional institutions, example Kenya institute of Public Relations, for professional accountability. 


\section{Differentiation Strategies}

Differentiation strategies distinguish an institution's services from its competing counterparts based on institutional strengths (Okat \& Solak, 2020; Šerić, OzretićDošen \& Škare, 2020). Therefore, strategies in the study context is a respond to, "what, why" and is flexible.

Therefore, differentiation strategies entail corporate branding, corporate image and (CVI) corporate visual identity (Sardana, 2018; Palazzo, Foroudi, Kitchen \& Siano, 2020). Corporate strategy, in this study is content, is the blue print institutional strategies to communicate. Guetterman et al. (2015) insisted on engaging the community in the dissemination, implementation and improvement of health-related research as proposed in this study. According to Iglesias, Ind and Schultz (2020), corporate branding entails using corporate image, identity to achieve differentiation strategy. Thus, create a distinctive institutional perception in the mind of the stakeholder, of the services rendered affirms, Palazzo et al. (2020).

Therefore, a strategy of creating a matchless impression of an institution's services. In context with the study, KEMRI's corporate strategies projecting or communicating research outcomes. Therefore, utilise corporate image, corporate identity as tools. Corporate image is the collective evaluation or perception of an institute's ability to deliver valued outcomes from its stakeholders about its services (Van Ruler, 2018; Sardana, 2018). Corporate image is the perception (at a stipulated time) of an organisation in the mind of its stakeholders (what an institute is). Once the name is referred to in its communications. Hence, how an institution is and how it operates thus, "How we would like others to see us", is what the aspired (Frandsen \& Johansen, 2018). In this case, KEMRI's image in stakeholders minds.

The corporate identity is a combination of colour scheme and design, communicating a visual statement about what it does. Thus, the corporate visual identity system (CVIS) comprises five aspects; authenticity, consistency, distinctiveness, transparency, visibility (Melewar et al., 2017; Okat \& Solak, 2020).

These are; the institute's or organisation name, slogan, logo, colour, symbol, typology. Foroudi, Melewar and Gupta, (2017) summarised them as elements of a corporate logo. That is, the official graphical design for an organisation and the uniqueness of the design requires significant creativity, which must match an organisations strategy and identity. Provides recognisability hence, increased familiarity. Scholars also refer to them as, corporate identity mix (Melewar et al., 2018; Gupta, 2018).

Moreover, CVI entails utilisation of graphical elements examples; colour, texttypography, logo photography and text). Therefore, CVI anchors corporate identity through the dimensions of visibility and distinctiveness. While informing KEMRI's stakeholders that, it exists (Okat \& Solak, 2020; KEMRI, 2020). Hence, distinguishes 
KEMRI's research outcomes from other research institutions. In the study content, corporate visual identity referred; to the organisation name is KEMRI. Whose slogan is, "In Search of Better Health", logo, typology is Times New Roman 12 or Calibri Light 12. Colour is sky navy blue in KEMRI's logo and publications. Thus, identifies KEMRI dealing with human health research in Kenya (KEMRI, 2020).

KEMRI's identity is not affected by its financial stability and success. Conveyed in its Japanese designed buildings, printed on official stationary used to communicate. Corporate identity is as organisational personality, identity as organisational as visual image, organisational as a collection of corporate communication. The corporate identity is based on organisational common goals and shared understanding. Hence, what an organisation is and how it operates (Rowden, 2017). Thus, how KEMRI perceives itself. The overall purpose is to achieve the organisations desired image from stakeholders (Cornelissen \& Cornelissen, 2017; Sardana, 2018). Example, KEMRI's corporate communication about its research breakthroughs.

Corporate visual identity is perception in the mind of KEMRI's management. "How we see ourselves" or How we would like others to see us" (Melewar et al., 2018). Examples are the colours, logo that differentiates KEMRI. A mental image or photograph. This is a construction of internal constituencies (internal stakeholders). Perceived by employee image, consumer image, community image and investor image. Scholars summarise corporate visual identity as the inward and outward looking of an institute or organisation to its stakeholders (Melewar et al., 2018; Rowden, 2017). The inward and outer perspective created via an organisation corporate communication outputs (Melewar et al., 2018).

Melewar study concludes that strategy and identity are the key in promoting integrated corporate communication. Thus yielding stakeholder commitment, loyalty and trust (Melewar et al., 2017). Therefore, relevant to KEMRI's corporate communication strategies with its stakeholders.

This study intended to fill the gaps in Melewar's study done in UK, which required further studies conducted to investigate if their study findings apply in other settings. Therefore, prompting this case study to be done in a Kenyan research institution. In addition, Melewar's study on taxonomy explained; behaviour, communication, culture, design and industry as key ingredients in corporate identity Thus, the individual character to which an institute is identified or recognised. Hence, KEMRI's name besides being an identification is a motivator to engage (communicate) in research. Therefore, there is a relationship between corporate strategy and corporate identity (Melewar et al., 2017).

\section{Corporate Communication Plan}

Corporate communication plan, comprises organisational plans or guidelines, for ascertaining; when and which situations to utilize formal or informal communication, 
stakeholder prioritisation, and communication structure. How communication flows from and outside of the organisation, either top-down or bottom-up (Bütschi, 2018; LaBelle \& Waldeck, 2020).

Therefore, corporate communication plan is the organisational communication protocol for informing and organisational stakeholders (Bütschi, 2018). Example, KEMRI is standard operating procedures ( $\mathrm{SOP}^{\prime} \mathrm{s}$ ) for communication. The official communication protocol used to disseminate information, internally and externally. Hence, based on a fixed time-fame, "by when" and "how", internal and external communications are done within KEMRI's budget (Sony, 2019). Example, increase utilise corporate communication strategies to enhance public health literacy by $50 \%$ from the year 2021 to 2026.

Moreover, Brownson et al. (2018), study realised that, only 15\% of health researchers use social media as a dissemination tool. Furthermore, that among the 100 most-covered 2016 journal articles, health studies were discussed on social media more than any other science topic. Hence, corporate communication plans, are utilised to disseminate information, internally and externally (Sony, 2019).

Therefore, a corporate communication plan entails guides on how the internal and external communications are done. Hence, a plan for determining; when, who, which information will be delivered, and in what channel (Eparkhina, Moreau, Köstner, Reilly, Ortiz, Tintore, Barbier \& Giusta, 2020). Example, how to communicate with the stakeholders like finding agencies or its staff pertaining various issues.

In addition, a corporate communication plan, determines what media channel to use, and when (Lo Presti \& Marino, 2020). Thus, the corporate communication plan gives guidelines or rather stipulates, what to whom, and who is allowed to communicate (Keyton, 2017; Taimio, 2020). Example, who and whom Corporate Affairs (CA) in KEMRI sends emails or press releases (KEMRI, 2020).

Moreover, the growth (proliferation) of ICT has necessitated institutions to strategically device plans to communicate. What needs to be communicated, to which stakeholder, in what manner, when and what effect, affirms Sinha and Bhatia, (2016).

Purtle, Lê-Scherban, Wang, Shattuck, Proctor and Brownson (2018) study recommended audience segmentation for policy developers. Therefore, audience segmentation are the dissemination strategies for customizing information destined for the different organisational publics. Therefore, the strategies for prioritising or articulating, the flow of communication internally and externally (Keyton, 2017). In this study's content, the selection of the corporate communication plan that best communicate the research outputs.

Another recent study by Yuan, (2019) was a comparative analysis of the Chinese and Japanese, corporate communication on Facebook and Twitter. Hence, the use of international social networks site (SNS) to communicate with stakeholders. Hence, to evaluate public responses and complains. The study summarised, "seeking 
feedback" as the highest response on Facebook, as compared to "promoting sales" from Twitter from the society.

Murunga et al. (2020) pointed out that; researchers using Knowledge Translation (KT) and face challenges at individual and institutional levels. These comprise; limited KT knowledge and skills, for communicating research and interacting with research end-users, inadequate institutional guidelines, and structures for promoting KT practice. Kenyan research institutions are obligated or mandated to communicate research information (outcomes) to the diverse stakeholders (Ministry of Health, 2020).

\section{Dissemination of Research Outcomes}

Dissemination of research outcomes refers to the distribution of scientific results also referred to as findings from disease surveillance programmes which entail; collection of information to control diseases. Diseases are a particular quality or disposition regarded as adversely affecting an individual or people (Bake \& Isaacs, 2018).

According to Starovoytova (2017), dissemination of research outcomes is the culmination stage of a study. Starovoytova's (2017) study reported $82 \%$ of their respondents disseminated their research outcomes in open access journals. Dissemination is planned, using evidence based interventions to targeted audience (Starovoytova, 2018). Relevant to this study, communication of scientific evidence shared to study participants.

Brownson, Eyler, Harris, Moore and Tabak (2018) study affirmed that; dissemination relies on the message, source, audience and the channel used. The study recommendations comprised; messages need to be framed or aligned to the target audiences. Journal articles cannot be relied on. Additional channels to include; policy briefs, news media, one on one meetings, seminar and workshops. Policy developers need to make policies that advocate for open access to aid the issue of not accessing scientific information.

Wong, Hernandez and Califf (2018) study recommended, returning research results to study participants. Wong et al. (2018) urged that; returning results is a basis for structured environment for developing an empirical framework. However, researchers and study respondents have the challenge of how to consume, analyse to make sense of the data.

Disease surveillance is the monitoring of disease patterns and progression in a community. These include disease reporting as a final stage (Cornelissen and Cornelissen, 2017). According to World Health Organisation (WHO) report dated November 19, 2018, on the status of diseases surveillance.

Surveillance entails tracking of the disease and programmatic responses, and taking action based on the data received. Currently, many countries with a high burden of malaria have weak surveillance systems and are not in a 
position to assess disease distribution and trends, making it difficult to optimize responses and respond to outbreaks... Effective surveillance is required at all points on the path to malaria elimination and the recommends that countries transform surveillance into a core intervention. Strong malaria surveillance enables programmes to optimize their operations.... Global Technical Strategy for Malaria 2016-2030 (WHO, 2018).

Kenya Medical Research Institute (KEMRI), has many departments researching on different diseases. Corporate communications strategies are used in human health research institutions to disseminate research outcomes. The communication process in an institution for the mutual interests with the publics (KEMRI, 2020). In Kenya, Kariuki et al. (2019) explored the research dissemination strategies used by KEMRI scientists. The study conclusions were that; researchers disseminated research outcomes in; international peer reviewed journals (92.7\%) between 2002 and 2015. Hence, confirms scientific community benefited more than the study respondents.

\section{Theoretical Framework}

This case study was anchored on excellence theory and communication theory (Choi, 2020). Commination scholars agree that theories comprise set of relationships, concepts, prepositions. Furthermore, theories are actually statements that create understanding by describing and explaining a phenomenon, prompting or justifying a cause for action (Kumar, 2019). Theories represent ways in which an environment is observed (Littejohn 1983, in Zerfass et al., 2018).

\section{Excellence Theory}

Developed by James E. Grunig, David M. Dosser and Larissa A. Grunig between 1970 and 1985, resulting from a study of best practices on corporate communications. Supported by (IABC) International Association of business communicators, incorporated additional theories of public relations roles, diversity, operations research and gender. Furthermore, excellence theory has developed into a general theory of public relations as a strategic management function. Excellence theory attributes value of institutes maintaining good public relations in with its strategic publics. Later developed to a global public relations theory. Hence, achieve mutual goals. The main advantage is that; organisations can save of costs from; litigation, legislation, negative publicity and regulation by maintaining favourable relations (Oliveira, 2019).

Excellence theory foundation is that; institutions ought to communicate with their publics symmetrically. Identify publics who can be affected by their decisions (like stakeholders theory). Therefore, the theory advocates integration stakeholders 
(scientists and respondents) and an institute's corporate communications. That, two way communication is ideal. Furthermore, reduce costs of negative publicity; provide products and services needed by their stakeholders (Oliveira, 2019). The theory of founded on four pillars. The goal-attainment approach; Institutions are deemed effective when they meet their objectives.

The theory is further criticised, as it values stakeholders than organisational values (Palazzo, Foroudi, Kitchen \& Siano, 2020). The excellence theory is relevant to this study as it facilitates to examine KEMRI's differentiation strategies and the corporate communication plan. The aim or objective being maintaining excellence in relating with its stakeholders to achieve institutional goals.

\section{Communication Theory}

Communication theory was developed in the 1920 's, by then referred to as the information theory. The pioneers being Clade Shannon between 1916 and 2001. Developing into the mathematical theory of communication (Choi, 2020). Shannon's focus being encoding information sent message. That a sender wants to transmit (van Ruler, 2018).

According to Klyukanov and Sinekopova (2019), the main elements of communication theory comprise; source, encoder, message, medium, receiver, decoding noise and the feedback. Therefore, communication theory is relevant to this study; since it facilitates comprehension of human communication acts. KEMRI's corporate communications are target internal and external stakeholders. The internal being the KEMRI staff, research collaborators. External stakeholders include; study respondents, Kenya government and suppliers.

Communication theory elaborates or explains production of information, transmission of information, methods to relay it, how meaning is shared, hence created (Choi, 2020). Therefore, differentiation strategies and corporate communication plan are important considerations for KEMRI's management.

Van Ruler, (2018) pointed out; three lenses how the communication process works. Communication as a one-way process of meaning construction whereby; the sender attempts to construct or reconstruct the meaning developed by the receiver. Communication is a two-way process of meaning construction. Example, is two or more people constructing new meanings together. Hence, communication is omnidirectional diachronic process, of meaning construction. Whereby the focused on, ongoing development of meaning itself.

Moreover, Zerfass et al. (2018) points out that, communication theories propose three lenses of communication. First, the one way process in which meaning construction is developed the sender from the receiver's point of view. Thus, the sender attempts to reconstruct meaning developed by the receiver. Secondly, in the two-way communication, the two individual construct the meanings together). Third, 
communication is omnidirectional diachronic process of meaning construction. The idea being meaning is created continuously (Sony 2019).

The modern of communication or contemporary model of communication was modified from Shannon and weaver model of communication includes feedback (see Figure 1, model of communication).

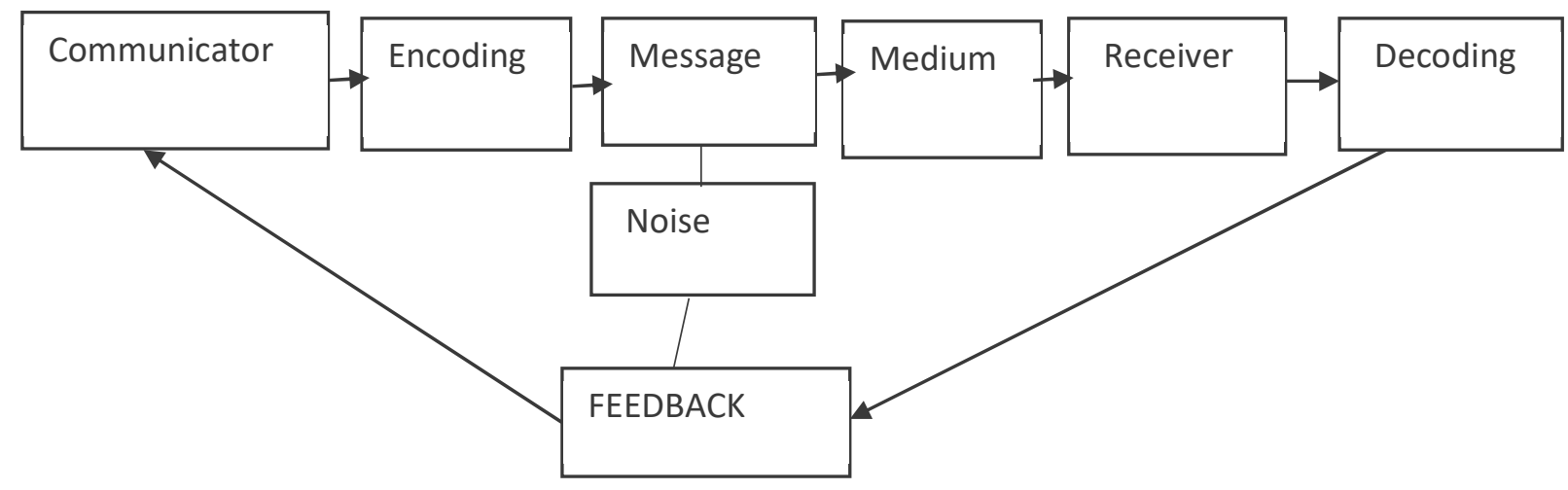

Figure 1. Contemporary Model of Communication Modified from Shannon and Weaver's Model of Communication. Source: van Ruler, 2018.

Figure 1, illustrates the process of the contemporary model of communications starting from; communicator, encoder, message, medium, receiver, decoding noise and the feedback link. Moreover, Figure 1 illustrates the communication of research outcomes as being feedback, to research respondents. Thus, corporate communication strategies proposed by this study are guided by the seven elements of communication from the; sender (KEMRI), ideas, encoding, communication channel, receiver, decoding and most important; feedback to study respondents (Kourakos, 2017).

Communication theory is therefore, relevant to this study as it examines the study variables. Therefore, communication theory is relevant to this study; since it facilitates comprehension of human communication acts. Thus, investigating the multiple layers of communication as interconnected, as opposed to isolated communication act, Karnaukhova and Polyanskaya (2016) study affirmed communication essential an organisation. Linked them to communications theory, public relations and corporate management. KEMRI's corporate communications are internal and external stakeholders. The internal being the KEMRI staff, research collaborators. External stakeholders include; study respondents, Kenya government and suppliers. Therefore, differentiation strategies and corporate communication plan are tailored (strategised) and unique stakeholder's interests.

In addition, and as an example, the power interest matrix might facilitate an organisations management accord the necessary attention to each stakeholder. As illustrated in the Table 1. The power interest matrix assess the level of interest for each stakeholder. Example, the funding agents (research collaborators or partners) require 
reports communicated say quarterly, of study progress and research highlighting breakthroughs or study findings (Yuan et al., 2017).

Table 1: Power Interest Matrix

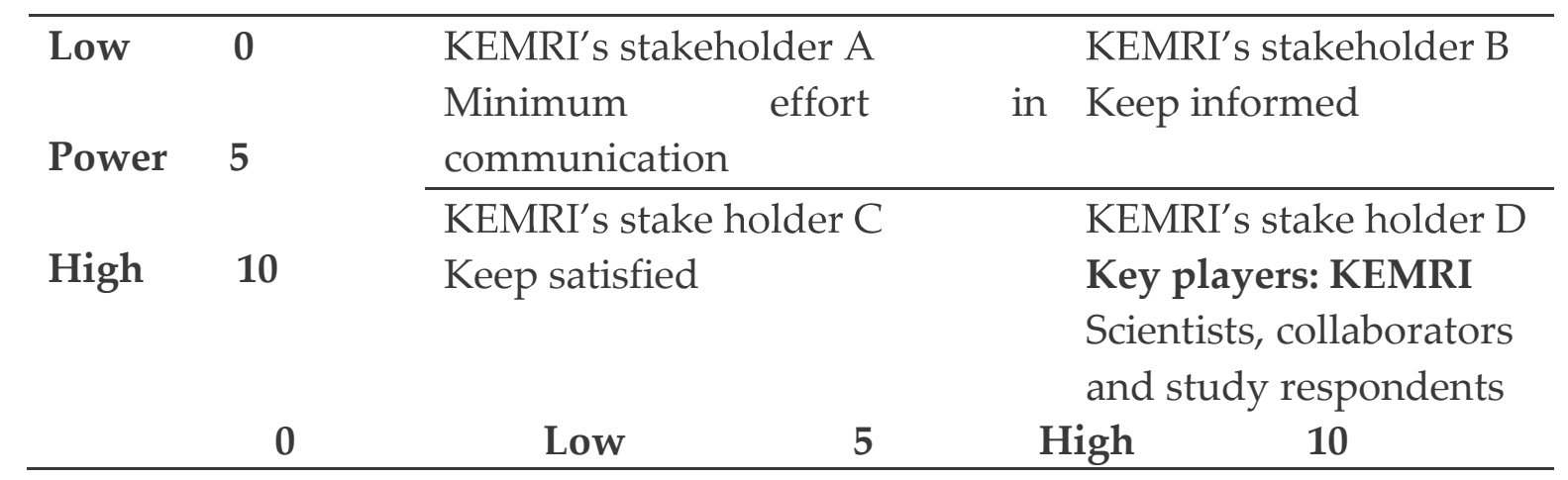

Level of interest

Source: Mendelow's Matrix (Eden \& Ackermann 1998, in Berényi, 2017)

Table 1 illustrates the priority given for KEMRI's stakeholder D Key players. KEMRI Scientists, collaborators and study respondents to be in constant communication. Thus, given priority or preference in KEMRI's corporate communication. Hence, illustrates the study respondents shift, to the "key players" quadrant marked "D", notably the level of interest is "high". The power interest matrix is an adoption from Mendelow's matrix (Power interest grid). According to Berényi (2017), the power interest grid helps generate stakeholder management. Thus, focusing on project and corporate level communications.

Nwachukwu (2017) observed that, institutions have an obligation to communicate facts to their stakeholders. These facts revolve around operations, achievements, problems (concerns, challenges or issues), plans prospects and intentions.

In addition, Yuan et al. 2017 advocated for a two-way communication. Whereby, communication flows between an institute and its stakeholders. This ensures it remains in operation. The study highlights were; the role of two-way communication dialogical communications between researcher and the community (public). Feedback is given preference in an organisation's communication decisions and in policy development (Yuan et al., 2017).

This is ideal if adopted by KEMRI's management in when choosing the differentiation strategies and corporate communication plan to communicate with the study respondents. Thus, adjustments done to accommodate organisations publics (see Figure 2.1, contemporary model of communication).

Communication theory is relevant in this case study, because of the study respondent's interest in getting the research outputs. Therefore, a research institution 
needs the input of research respondents to generate the research outputs as the theory proposes the interconnected relationship between organisation and its stakeholders. Moreover, communication theory facilitates the understanding of the communication process (van Ruler, 2018). In context to this study, the communication process that originating from KEMRI and destination being study respondents.

Communication theory is applicable in this study of corporate communication strategies. This is because; it highlights the role of corporate communication process. Thus, the interpretation of research outputs to respondents. In relation to this study, KEMRI's Corporate Affairs is part of the KEMRI management. Hence, the scalar chain (in administrative theory) as proposed by Henri Fayol's 14 principles of management, between 1845 and 1925. Which affirmed that there should be proper communication flow and authority (Edwards, 2018). Since it, controls the communication activities with its overall environment. Furthermore, characters of communication theory paradigm comprise; communication focused on sender and receiver. Thus, KEMRI as an institution communicates through diverse departments and units. Hence, KEMRI through its researchers adopts to the change in environment by translating or identifying corporate communication strategies to communicate the research outcomes. The limitations of communication theory are that; it concentrates in inflow and out flow of information; the process is not automatic and is complicated. Therefore, dependent of human intervention (Berger, Calabrese, Ellul, Adorno, Horkheimer, Barthes \& Castells, 2018). Examples, identifying the study focus or deciding, what to study when everything is interconnected.

\section{Discussion}

This case study answered two research questions. First, what are the differentiation strategies for dissemination of disease surveillance research outcomes to study respondents at KEMRI? The second, How does the corporate communication plan determine the dissemination of disease surveillance research outcomes to study respondents at KEMRI?

Therefore, the research utilised findings from quantitative and qualitative indicated. An increase in the determinant yielded an increase in the dependant variable. Majority of the respondents agreed differentiation strategies and the corporate communication plan in place influenced dissemination of disease surveillance research outcomes at KEMRI. However, a few declined. Study participant's opinion varied in the degree of agreement or disagreement.

The qualitative data equally supported the qualitative findings, and aligned to

excellence theory and communication theory propositions (Choi, 2020). Further based on, the correlation between the study variables; corporate communication strategies (differentiation strategies, corporate communication plan) and dissemination of research outcomes. The findings concur that, differentiation 
strategies influenced the respondents to trust the research outcomes. Conversely, KEMRI's communication plan, stipulated, how research outcomes were communicated.

Study participant's opinion varied in the degree of agreement or disagreement. Participants 7, 4 and 2, supported differentiation strategies. Finally, participants 3, 5 and 10 opinions supported the communication plan in place at KEMRI.

The findings confirmed that, KEMRI maintained good corporate communications (public relations) it strategic publics as prosed in, excellence theory attributes value of organisations and mutual relations. The study's corporate communication strategies (differentiation strategies and the corporate communication plan) aligned to the two-way communication, That is, communication and interpretation of research outputs to respondents. Ultimately, KEMRI's stakeholder's interests valued as proposed in communication theory.

The study participants in context this study were; individuals (scientists at KEMRI and KEMRI study respondents) purposely chosen to respond or answer study questionnaires and interviews. Derived from the sample size by a researcher (Blake \& Priest, 2019).

The study respondents in context with this study were, individuals selected to participate in a study by a scientist also referred to as a principle investigator (PI). Respondents were required to respond or answer questionnaires. Individuals from KEMRI study cohorts (share the characteristic of being members from on-going KEMRI projects). The study subjects of study investigations on a social problem, example disease burden (Blaikie \& Priest, 2019; Ghauri, Grønhaug \& Strange, 2020).

This study findings contributed to the existing body of corporate communication to specifically identify; ideal corporate communication strategies that; include study respondents as stakeholders in disease surveillance research outcomes dissemination.

\section{Conclusions}

In conclusion the study answered the research questions; (1) that are the differentiation strategies for dissemination of disease surveillance research outcomes to study respondents at KEMRI? (2) How does the corporate communication plan determine the dissemination of disease surveillance research outcomes to study respondents at KEMRI? First, the study summarised differentiation strategies comprised image and identity, as key elements for dissemination of disease surveillance research outcomes to study respondents at KEMRI.

Secondly, the corporate communication plan in place had a significant role for dissemination of disease surveillance research outcomes to study respondents at KEMRI. These study findings affirm that; scientists ought to communicate science (research outcomes) to the study participants and the government, which constitutes 
the policymakers. Furthermore, this study distinguished the research outcomes as an incorporation of; recommendations, conclusions (answers why) and findings of the ongoing research studies, in human health at KEMRI in 2020. Whereas, findings are as result of process involving an input, output process or consequences. Findings referred to as the results, the evidence from literature hence, and the research data, in this study. KEMRI communicates research outcomes as feedback, as media content for the fourth estate and persuade their uptake by its stakeholders to remain relevant.

To enhance its differentiation strategies implement Integrated Marketing Communication (IMC). Since it is an element of the corporate communication, incorporate marketing department into CA department, to curb duplication of resources (Šerić, Ozretić-Došen \& Škare, 2020).

Hence, propagate unified, consistence in messaging, identifying KEMRI as an authority in communicating research outcomes (Muhammedrisaevna, Bayazovna \& Kakhramonovna, 2020; KEMRI, 2020).

This study contributed to the existing body of corporate communication to specifically identify; ideal corporate communication strategies that; include study respondents as stakeholders in research outcome dissemination. Thus, add to the available scant literature, which is not comprehensive on corporate communication strategies to disseminate human research outcomes in Kenya. Nwachukwu (2017) observed that institutions have an obligation to, strategically communicate with to their stakeholders. Wong, Hernandez and Califf (2018) study also recommended; sharing (feedback) of research results to study participants. The study findings further alluded that; corporate communication strategies take up the intermediary's role of; packaging and disseminating research outcomes. Lastly, this case study in Kenya responded to gaps in (Melewar et al., 2017) study done in UK. Which required further studies to be conducted to assert if, their study findings apply in other settings.

\section{Recommendations}

The study therefore recommended the following recommendations for KEMRI. Enhancement of the differentiation strategies will entail continually maintaining image, identity and corporate visual identity (Okat \& Solak, 2020; Kankam-Kwarteng, Osman \& Acheampong, 2020). This would propagate unified, consistence in messaging, identifying KEMRI as an authority in communicating research outcomes. The communications are tailored with the audience (study respondents) needs in mind (Zahra, 2018). Therefore, the KEMRI study respondents to be incorporated in dispatched research outcomes.

In addition, empower CA staff to manage; media relations, identity, reputation and media audits (LaBelle \& Waldeck, 2020). Communication plan; elevate CA department to top management, to manage the communication plan for disseminating research outcomes. KEMRI to incorporate a corporate communication 
plan for scientists and CA for translating research jargon to research respondents and other stakeholders (Rakedzon et. al., 2017; Zerfass et al., 2018). Farrell, Kagan and Tisdall (2016) also suggested the need to alter to simpler language on research outcomes (evidence) presented in complex and technical jargon,

Therefore, this research study's contribution to corporate communication knowledge on differentiation strategies and corporate communication plan are as follows. Enhancement of differentiation strategies by implementing IMC, incorporate marketing department into C.A department, to curb duplication of resources. Hence, propagate unified, consistence in messaging, identifying KEMRI as an authority in communicating research outcomes. KEMRI should develop KEMRI differentiation strategies by including, strategies that will continually maintain the identity, image, reputation and thus overall CVI. An example is, identify CA staff dedicated to periodic identity audit and reputation maintenance.

The study affirmed the differentiation strategies in KEMRI comprised corporate branding (image and identity) and CVI through the dimension of distinctiveness. They ought to be updated regularly to adopt the dynamic environment. KEMRI's logo and colour distinguishes research outcomes to study respondents, maintains relevance, trust among competing counterparts and consumes of research outcomes.

The study contributions on corporate communication plan comprised; place KEMRI's Corporate Affairs (CA) department in top management, to coordinate or manage the communication plan for disseminating research outcomes. KEMRI to incorporate a communication plan for scientists and CA on translation research jargon to research respondents (stakeholders).

This research work focused on corporate communication strategies (differentiation strategies and corporate communication plan) for dissemination of disease surveillance research outcomes at KEMRI. Therefore, this study recommends that a study be conducted longitudinally in all KEMRI outstations. Hence, enhance generalisation of the findings across Kenya. This research work was limited to differentiation strategies and corporate communication plan as corporate communication strategies. Thus, created a foundation for studies to investigate other corporate communication strategies besides differentiation strategies and corporate communication plan as corporate communication strategies for dissemination of disease surveillance research outcomes.

\section{References}

Choi, S., 2020. When digital trace data meet traditional communication theory:

Theoretical/methodological directions. Social Science Computer Review, 38(1), pp.91-107. 
Chatzidamianos, G. and Parker, R.J., 2020. Using information and communication technologies for health research. In Handbook of Theory and Methods in Applied Health Research. Edward Elgar Publishing.

Creswell, J. W., \& Creswell, J. D. (2017). Research design: Qualitative, quantitative, and mixed methods approaches. Sage publications.

Blaikie, N., \& Priest, J. (2019). Designing social research: The logic of anticipation. John Wiley \& Sons. Psychology and health, 13(4), 623-649.

Berger, C., Calabrese, R., Ellul, J., Adorno, T., Horkheimer, M., Barthes, R., \& Castells, M. (2018). Communication theory.

Brownson, R. C., Eyler, A. A., Harris, J. K., Moore, J. B., \& Tabak, R. G. (2018). Research full report: getting the word out: new approaches for disseminating public health science. Journal of Public Health Management and Practice, 24(2), pp.102.

Brownson, R. C., Colditz, G. A., \& Proctor, E. K. (Eds.). (2018). Dissemination and implementation research in health: translating science to practice. Oxford University Press.

Braun, V., Clarke, V., Hayfield, N., \& Terry, G. (2019). Thematic analysis. Handbook of Research Methods in Health Social Sciences, 843-860.

Burkholder, T., \& Buchanan, J. (2019). 11 Interactions with Consultants. Communication in Emergency Medicine.

Bütschi, G. (2018). Communication Planning. The International Encyclopedia of Strategic Communication, pp.1-11.

Dixon, M.A., 2017. Corporate Communication. The International Encyclopedia of Organisational Communication, pp.1-11.

Edwards, R. (2018). An Elaboration of the Administrative Theory of the 14 Principles of Management by Henri Fayol. International Journal for Empirical Education and Research, 1(1), 41-51.

Eparkhina, D., Moreau, K., Köstner, N., Reilly, K., Ortiz, V., Tintore, J., Barbier, M. and Giusta, E., 2020. Communication Plan.

Etikan, I., \& Bala, K. (2017). Sampling and sampling methods. Biometrics $\mathcal{E}$ Biostatistics International Journal, 5(6), 00149.

Farrell, A., Kagan, S.L. and Tisdall, E.K.M., 2016. Early childhood research: An expanding field. The sage handbook of early childhood research, pp.1-11.

Frandsen, F., \& Johansen, W. (2017). Strategic communication. The international of encyclopedia of organisational communication, pp.1-9.

Frandsen, F. and Johansen, W., 2018. Corporate communication. The International Encyclopedia of Strategic Communication, pp.1-10.

Green, J., \& Thorogood, N. (2018). Qualitative methods for health research. Sage. 
Kankam-Kwarteng, C., Osman, B. and Acheampong, S., 2020. Performance of restaurants: Recognizing competitive intensity and differentiation strategies. Journal of Tourism, Heritage \& Services Marketing, 6(3), pp.25-34.

Karnaukhova, N.A. and Polyanskaya, E.V., 2016. Communication and reputation as essentials for the positioning of an organisation. AI \& society, 31(3), pp.371379.

Kariuki, J.N., Kaburi, J., Musuva, R., Njomo, D.W., Night, D., Wandera, C., Wodera, J. and Mwinzi, P.N., 2019. Research Dissemination Strategies Used by Kenya Medical Research Institute Scientists. EA Health Research Journal, 3(1), pp.7078.

Keyton, J. (2017). Communication in organisations. Annual Review of Organisational Psychology and Organisational Behavior, 4, pp.501-526.

Koprowska, J. (2020). Communication and interpersonal skills in social work. Learning Matters.

Kourakos, M., Fradelos, E. C., Papathanasiou, I. V., Saridi, M., \& Kafkia, T. (2017). Communication as the Basis of Care for Patients with Chronic Diseases. American Journal of Nursing, 7(3-1), 7-12.

Klyukanov, I. E., \& Sinekopova, G. V. (2019). Communication theory through the ages. Routledge.

Kumar, R. (2019). Research methodology: A step-by-step guide for beginners. Sage Publications Limited.

Kunczik, M. (2016). Images of nations and international public relations. Routledge.

LaBelle, S., \& Waldeck, J. H. (2020). Strategic Communication for Organisations. University of California Press.

Lo Presti, L. and Marino, V., 2020. Is online public engagement a new challenge in the university communication plan? A managerial perspective. Studies in Higher Education, 45(7), pp.1380-1397.

Okat, Ö., \& Solak, B. B. (2020). Visuality in Corporate Communication. In New Media and Visual Communication in Social Networks (pp. 37-59). IGI Global.

O'Cathain, A., 2020. Mixed Methods Research. Qualitative Research in Health Care, pp.169-180.

Mack, W., 2018. Vox populi, vox deorum? Athenian document reliefs and the theologies of public inscription. Annual of the British School at Athens, 113, pp.365-398.

Maiorescu-Murphy, R.D., 2020. New Directions for Theory and Practice. In Corporate Diversity Communication Strategy (pp. 193-210). Palgrave Macmillan, Cham.

McElfish, P. A., Purvis, R. S., \& Long, C. R. (2018). Researchers' experiences with and perceptions of returning results to participants: Study protocol. Contemporary clinical trials communications, 11, pp.95-98. 
Melewar, T.C., Foroudi, P., Gupta, S., Kitchen, P.J. and Foroudi, M.M., 2017. Integrating identity, strategy and communications for trust, loyalty and commitment. European Journal of Marketing.

Muhammedrisaevna, T.M.S., Bayazovna, G.N. and Kakhramonovna, D.A., 2020. Goal and objectives of integrated marketing communications. Economics, (2 (45).

Mohamad, B. and Bakar, H.A., 2018, March. Corporate communication and strategic management: history, operational concept and integration. In 15th International Symposium on Management (INSYMA 2018). Atlantis Press.

Mohamad, B., Nguyen, B., Melewar, T.C. and Gambetti, R., 2018. Antecedents and consequences of corporate communication management (CCM). The Bottom Line.

Murunga, V.I., Oronje, R.N., Bates, I., Tagoe, N. and Pulford, J., 2020. Review of published evidence on knowledge translation capacity, practice and support among researchers and research institutions in low-and middle-income countries. Health research policy and systems, 18(1), p.16.

Nwachukwu, F. G. (2017). Information Communication Technologies (ICTS) and Corporate

Communications Outputs A Critical Analysis. International Journal of Communication: An Interdisciplinary Journal of Communication Studies, 6(1).

Okat, Ö., \& Solak, B. B. (2020). Visuality in Corporate Communication. In New Media and Visual Communication in Social Networks (pp. 37-59). IGI Global.

Purtle, J., Lê-Scherban, F., Wang, X., Shattuck, P. T., Proctor, E. K., \& Brownson, R. C. (2018). Audience segmentation to disseminate behavioral health evidence to legislators: an empirical clustering analysis. Implementation Science, 13(1), p.121.

Purtle, J., Lê-Scherban, F., Wang, X., Shattuck, P. T., Proctor, E. K., \& Brownson, R. C. (2018). Audience segmentation to disseminate behavioral health evidence to legislators: an empirical clustering analysis. Implementation Science, 13(1), p.121.

Rakedzon, T., Segev, E., Chapnik, N., Yosef, R. and Baram-Tsabari, A., 2017. Automatic jargon identifier for scientists engaging with the public and science communication educators. PloS one, 12(8), p.e0181742.

Rowden, M. (2017). The Art of Identity: Creating and Managing a Successful Corporate Identity: Creating and Managing a Successful Corporate Identity. Routledge.

Ryen, A. (2016). Research ethics and qualitative research. Qualitative research, 31-46. Sardana, A. (2018). Corporate image building-A study of Indian corporate sector. Pranjana: The Journal of Management Awareness, 21(1), pp.23-29. 
Saido, G. M., Siraj, S., Nordin, A. B. B., \& Al-Amedy, O. S. (2018). Higher order thinking skills among secondary school students in science learning. MOJES: Malaysian Online Journal of Educational Sciences, 3(3), pp.13-20.

Šerić, M., Ozretić-Došen, Đ. and Škare, V., 2020. How can perceived consistency in marketing communications influence customer-brand relationship outcomes?. European Management Journal, 38(2), pp.335-343.

Shuster, J. J. (2019). CRC handbook of sample size guidelines for clinical trials. CRC Press. Sinha, M., \& Bhatia, P. (2016). Strategic corporate communication and impact in Indian service sector. Corporate Communications: An International Journal.

Sony, M. (2019). Implementing sustainable operational excellence in organisations: an integrative viewpoint. Production E Manufacturing Research, 1-21.

Starovoytova, D. (2018). Mastering Scientific Research Writing and Dissemination. LAP Lambert-Academic-Publishing, Germany.

Starovoytova, D. (2017). Scientific Research, Writing, and Dissemination (Part 4/4): Dissemination of Scholarly Publications. Journal of Education and Practice (USA), pp.2222-1735.

Taherdoost, H. (2016). Validity and reliability of the research instrument; how to test the validation of a questionnaire/survey in a research.

Taimio, A., 2020. Communication plan: cancelling an international conference.

Treadwell, D., \& Davis, A. (2019). Introducing communication research: Paths of inquiry.

SAGE Publications, Incorporated.

Van Ruler, B., 2020. An Underrated Pillar on Which Strategic Communication Rests. Future Directions of Strategic Communication.

Van Ruler, B., 2018. Communication theory: An underrated pillar on which strategic communication rests. International Journal of Strategic Communication, 12(4), pp.367-381.

World Health Organisation WHO. (2018; 2019; 2020) Centralised information system for infectious diseases (CISID).

Yuan, S., Oshita, T., AbiGhannam, N., Dudo, A., Besley, J. C., \& Koh, H. E. (2017). Two-way communication between scientists and the public: A view from science communication trainers in North America. International Journal of Science Education, Part B, 7(4), pp.341-355.

Zahra, I. M. (2018). Integrated Marketing Communications (IMC): The Interdisciplinary Concept. In Promoting Interdisciplinarity in Knowledge Generation and Problem Solving (pp.102-123). IGI Global.

Zerfass, A., Verčič, D., Nothhaft, H., \& Werder, K. P. (2018). Strategic communication: Defining the field and its contribution to research and practice. International Journal of Strategic Communication, 12(4), pp.487-505. 